\title{
Prevalence, predilection sites and pathological findings of Taenia multiceps coenuri in slaughtered goats from south-east Iran
}

\begin{abstract}
Authors:
Reza Kheirandish ${ }^{1}$

Masoud Sami

Shahrzad Azizi ${ }^{3}$

Mohammad Mirzaei ${ }^{1}$

Affiliations:

${ }^{1}$ Department of Pathobiology, Shahid Bahonar University of Kerman, Iran

${ }^{2}$ Department of Food Hygiene and Public Health, Shahid Bahonar University of Kerman, Iran

${ }^{3}$ Department of Pathobiology, Islamic Azad University, Shahrekord Branch, Iran

Correspondence to:

Reza Kheirandish

Email:

kheirandish@uk.ac.ir

Postal address:

Department of Pathobiology

Shahid Bahonar University,

Kerman, Iran

Dates:

Received: 30 Mar. 2012

Accepted: 14 Sept. 2012

Published: 29 Nov. 2012

How to cite this article: Kheirandish, R., Sami, M., Azizi, S. \& Mirzaei, M., 2012, 'Prevalence, predilection sites and pathological findings of Taenia multiceps coenuri in slaughtered goats from south-east Iran', Onderstepoort Journal of Veterinary Research 79(1), Art. \#436, 5 pages. http:// dx.doi.org/10.4102/ojvr. v79i1.436
\end{abstract}

C 2012. The Authors. Licensee: AOSIS OpenJournals. This work is licensed under the Creative Commons Attribution License.
Coenurosis is a zoonotic disease in a variety of ruminants caused by the metacestode of Taenia multiceps. The coenuri in the brain and spinal cord of sheep and goats have been identified as Coenurus cerebralis whilst those reported in other tissues have been named Coenurus gaigeri. This study was conducted during the spring and summer of 2011. Out of 25739 goats inspected in slaughterhouses, 23 carcasses $(0.09 \%)$ revealed one or multiple visible swellings on the different muscles and visceral organs. The coenuri, of variable sizes, were found mainly in the muscles of the thigh, shoulder and neck, and were less common in the abdominal muscles and subcutaneous tissues. Coenuri were also found in the diaphragm, tongue, intercostal muscles, lung, parotid area and tunica adventitia of the aorta in a goat with severe infection. The brains of slaughtered goats that had coenuri in their skeletal muscles were examined and coenuri were found in two specimens $(8.69 \%)$. The coenuri were located in the occipital lobe, the anterior part of the right cerebrum and the parietal lobe of the left cerebrum. Histopathologically, coenuri in the brain caused pressure atrophy and liquefactive necrosis in the surrounding tissues, hyperaemia, perivascular cuffing, neuronal degeneration, neuronophagia, satellitosis, diffuse microgliosis and astrocytosis. Coenuri in the skeletal muscles caused degenerative and necrotic changes, hyalinisation and myositis. In the lung, tissues around the coenurus revealed atelectasis and focal interstitial fibrosis. In the present study, concurrent occurrence of coenuri in the central nervous system and skeletal muscles supports the hypothesis that $\mathrm{C}$. cerebralis and C. gaigeri are different names for the metacestodes of the same species of tapeworm.

\section{Introduction}

Coenurosis (gid or sturdy) is a zoonotic disease caused by the metacestodes of Taenia multiceps in various livestock species. Coenurosis is an economically important disease as it causes serious problems in especially the sheep industry. Taenia multiceps inhabits the small intestine of the definitive hosts, which include dogs and wild carnivores. Carnivores are mainly infected by eating the uncooked offal of domestic animals, in which the larval stages of the tapeworms such as T. multiceps and Echinococcus spp. occur. When vegetation contaminated with eggs is ingested by the intermediate hosts - in this case ruminants - the oncospheres hatch in the small intestine and pass through the intestinal wall to reach the brain via the bloodstream, where they develop further (Soulsby 1982; Verster 1965). In addition to infecting the brain, the larval stage also develops in the subcutis and muscles, and in the body cavities (Schuster, Sivakumar \& Wieckowsky 2010). Intramuscular and subcutaneous coenuri are referred to as Taenia gaigeri by some authors (Boch \& Supperer 1983) whilst others regard it as synonymous with T. multiceps (Verster 1969; Verster \& Bezuidenhout 1972). The intermediate host apparently also plays a role in determining the kind of coenurus (Schuster et al. 2010; Soulsby 1982). Coenurus gaigeri, the metacestode of T. gaigeri has been reported in the subcutaneous tissues of sheep and goats. The morphological features of the coenuri occurring in the brain and other tissues have been reported to be similar (Soulsby 1982). The metacestode, especially in goats, have been documented with an alternative name, C. gaigeri (Bhalla \& Negi 1962; El Sinnari, Tageldin \& Sumri 1999; Sharma et al. 1995; Sharma \& Chauhan 2006).

This study was aimed at describing the pathological lesions caused by T. multiceps, the site of predilection, and the size and number of coenuri in different tissues of naturally infected goats.

\section{Materials and methods}

\section{Study area}

This study was performed in Kerman Province, Iran, during the spring and summer of 2011. The province of Kerman is in the south-east of Iran and covers an area of $181714 \mathrm{~km}^{2}$. The geographical latitude and longitude of this area is $30^{\circ} 15^{\prime} \mathrm{N}$ and $57^{\circ} 01^{\prime} \mathrm{E}$, respectively. Kerman city is located in an arid desert area with a semi-moderate and dry climate. The maximum and minimum 
temperatures reach $39.6{ }^{\circ} \mathrm{C}$ and $-7{ }^{\circ} \mathrm{C}$, respectively. Rainfall is irregular and scarce. The density of livestock animals in this area is 33 animals per square kilometre.

\section{Sample collection}

The carcasses of 25739 goats were inspected for coenuri (13 882 in the spring and 11857 in the summer) at the Kerman slaughterhouse in south-east Iran. The tissue locations, numbers and sizes of coenuri from each goat were recorded. The macroscopic and microscopic lesions of the coenuri were evaluated. The heads of the infected goats were separated from the rest of the carcasses, and after removing the skin, a cross-section was cut through the area just caudal to the frontal bone using a handsaw. This was followed by two parallel cuts on the parietal bone. The bone was removed using a chisel and hammer and the meninges were incised with a scalpel blade to expose the brain. The brain was examined for the presence of coenuri. The spinal cord was examined after the removal of vertebral arches.

\section{Pathological examination}

The coenuri and the surrounding tissues were fixed in $10 \%$ neutral buffered formalin for histopathological examination. The samples were dehydrated in graded ethanol and embedded in paraffin wax. Sections were cut at $5 \mu \mathrm{m}$ thickness, mounted on glass slides and routinely stained with hematoxylin and eosin. Each section was examined by light microscopy.

\section{Ethical considerations}

The study was approved by the local ethics committee of our faculty, in accordance with the ethics standards of the 'Principles of Laboratory Animal Care'.

\section{Results}

\section{Prevalence rate and predilection sites}

With regard to the prevalence rate and predilection sites of coenuri, 23 out of 25739 goats inspected in the slaughterhouse $(0.09 \%)$ revealed one or more visible swellings on the different skeletal muscles and visceral organs. Of the affected carcasses, 13 were found in spring and 10 in summer. The swellings were soft and pitted on pressure and varied from $2.1 \mathrm{~cm} \times 3.4 \mathrm{~cm}$ to $8.5 \mathrm{~cm} \times 10.2 \mathrm{~cm}$. Clear watery fluid and whitish clusters of scolices were visible through the thin and transparent wall of the coenuri (Figure 1). As shown in Figures 2 and 3, the coenuri were found mainly in the muscles of the thigh (15) and neck and shoulder region (10), whilst less frequently in the subcutaneous tissues and perineal fat (5) and abdominal muscles (3). Although the coenuri were usually observed at the superficial surfaces of affected muscles, they sometimes extended very deep into the muscles, especially in the neck region.

A total of 68 coenuri were recorded in a single carcass, with most located in the skeletal muscles. Single coenuri were found in the diaphragm, the intercostal muscles, the right lung, the pelvic cavity and at the base of the tongue

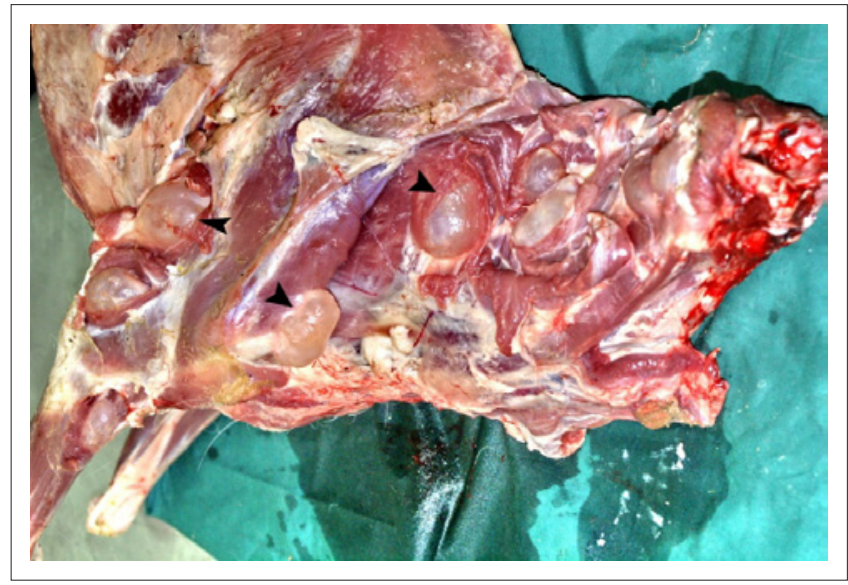

FIGURE 1: Multiple coenurui embedded superficially and deep between the muscles of the neck and shoulder (arrowheads).

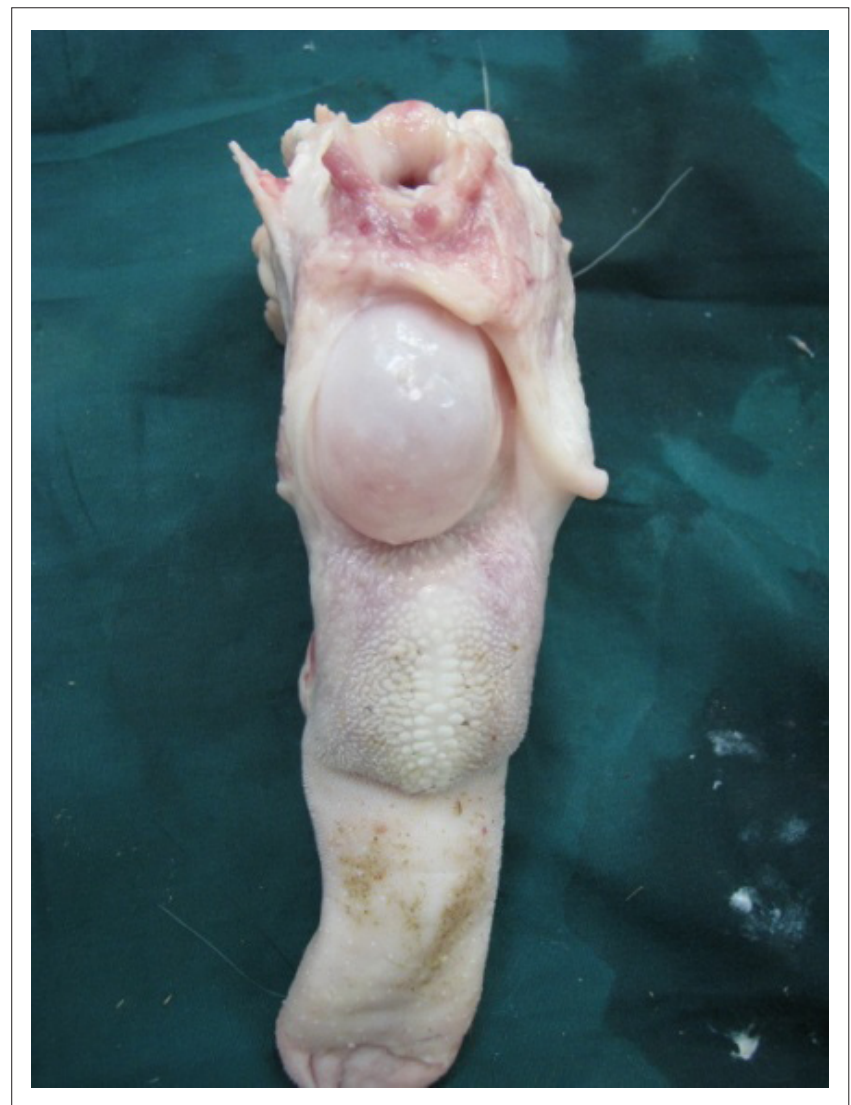

FIGURE 2: A coenurus at the base of the tongue.

(Figure 2). Single coenuri were also located in the tunica adventitia of the aorta above the base of the heart and close to the parotid gland. The brain was infected with three coenuri, of which two occurred in the occipital lobe of the right hemisphere and the other in the anterior part of the cerebrum near the olfactory lobe. Cerebral coenuri were detected in two of the 23 infected goats $(n=2 / 23,8.69 \%)$. In another case, the parietal lobe of the left cerebrum was infected with a single coenurus . None occurred in the spinal cord.

\section{Macroscopic and histopathologic findings}

Coenuri in the brain caused damage to surrounding tissues, including thinning of the cerebral grey and white matter 
owing to focal pressure atrophy and liquefactive necrosis. The meninges were hyperaemic and oedematous, and microscopically there were degenerative and necrotic lesions in the brain. Within the brain, sections of coenuri of various shapes were surrounded by marked eosinophilic necrotic tissues, degenerated neutrophils and mononuclear cells. A zone of chronic cellular reaction consisting of Langhans giant cells and mononuclear cells was present on the outer layer and a capsule of fibrous connective tissue enclosed the whole coenurus (Figures 3 and 4). Cerebral tissues around the coenuri revealed hyperaemia, perivascular cuffing predominantly comprising mononuclear cells, neuronal degeneration, demyelination, neuronophagia, satellitosis, diffuse microgliosis and astrocytosis. In the skeletal muscles, the metacestodes caused mechanical destruction with associated degenerative and necrotic changes, hyalinisation, and focal to diffuse inflammatory cell infiltration that included lymphocytes and eosinophils. In the lung, the coenurus caused atelectasis and focal interstitial fibrosis in the pulmonary parenchyma around the coenurus.

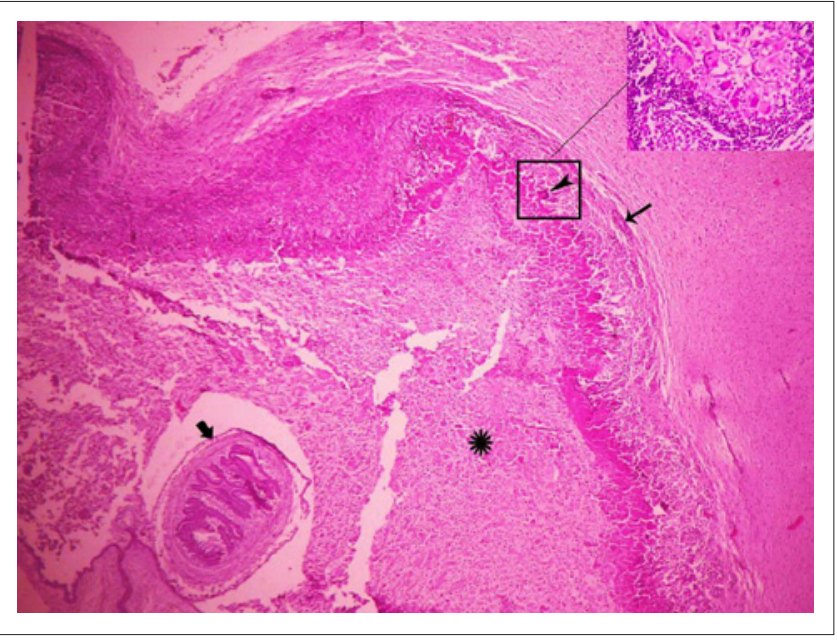

The thick arrow shows a section of metacestodes within the coenuri, surrounded by marked eosinophilic necrotic tissues. The asterisk indicates degenerated neutrophils and mononuclear cells, followed by a zone of Langhans giant cells and mononuclear cells (arrowhead). A tissue capsule of fibrous connective enclosed the coenurus (thin arrow). The giant cells and aggregation of neutrophils are shown in higher magnification in the insert (HE, $\times 100)$.

FIGURE 3: Microscopic features of coenurosis in the brain.

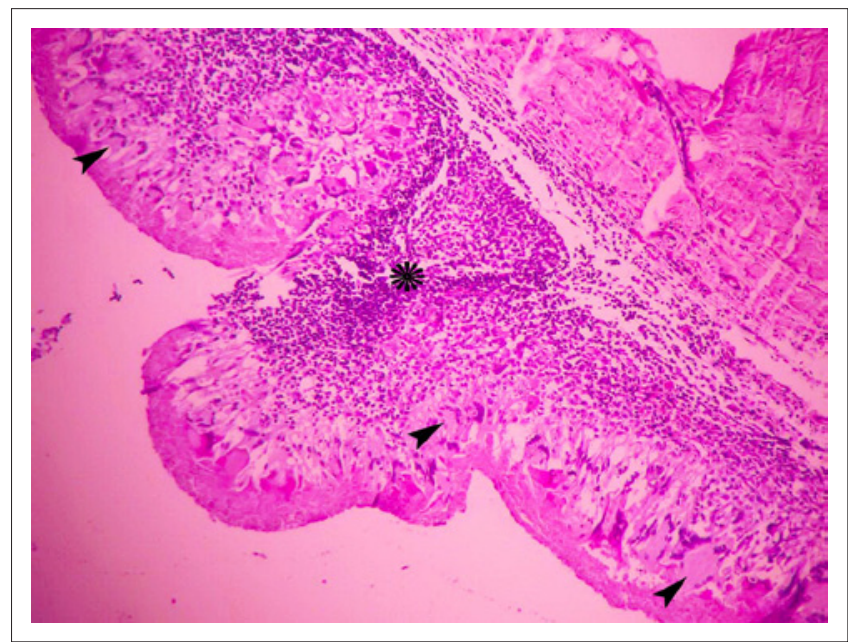

$\mathrm{HE}, \times 100$.

FIGURE 4: Inflammatory cells including giant cells (arrowheads) and neutrophils (astrisk) around the coenurus.

\section{Trustworthiness}

The investigators who undertook the gross observations and histopathological studies in the present study were unaware of the experimental design and grouping details. The histopathological studies performed blind by three different pathologists.

\section{Discussion}

Infection by the larval stage of the tapeworm T. multiceps in small ruminants is common worldwide (Oryan et al. 2010; Shivapraksh \& Thimma Reddy 2009; Uslu \& Guclu 2007), but rare in horses (ed. Fraser 1991), cattle (Avcioglu et al. 2011) and humans (Webbe 1994). Reports from Asian countries note the central nervous system and skeletal muscles as the main predilection sites in the intermediate hosts (Alim et al. 2002; Gosh et al. 2005; Islam et al. 2006; Moghaddar 2007; Oryan et al. 2010; Sharma \& Chauhan 2006). These sites have not been reported as often from countries outside Asia, for example in Sudan (Hago \& Abu-Samra 1980; Ramadan, Magzoub \& Adam 1973), Oman (El Sinnari et al. 1999) and Namibia (Bohrmann 1990).

Cerebral coenurosis occurs principally in sheep whilst extracerebral coenurosis is more common in goats. The clinical signs of the cerebral form include ataxia, hypermetria, blindness, head deviation, stumbling, paralysis, and head pressing and circling, and may be confused with other nervous diseases. The mortality rate may reach $100 \%$. In most cases, animals with muscle infections remain without clinical symptoms and are diagnosed only at slaughter (Soulsby 1982). In rare cases, treatment is administered (Verster \& Tustin 1990). Praziquantel and albendazole have been reported to be effective, with cure rates of $60 \%-85 \%$ in humans (Verster \& Tustin 1982). Coenuri in the skeletal muscles may cause muscular pain or impairment of movement and eventually result in recumbency (Sharma \& Chauhan 2006). Locomotory disorders in the hind limbs may be related to pressure on the sciatic nerve caused by coenuri (Ramadan et al. 1973).

The present study has investigated the prevalence and pathologic characteristics of coenurosis in slaughtered goats in Kerman Province, Iran. The prevalence of coenurosis was recorded as $0.09 \%(n=25739)$. The main tissues infected by coenuri were the muscles of the thigh, shoulder and neck, and less frequently the abdominal muscles, subcutaneous tissues and cerebrum. Single coenuri were found in the diaphragm, tongue, intercostal muscles, lung, parotid area and tunica adventitia of the aorta in a severely infected goat. The occurrence of coenuri in the tongue, parotid area and tunica adventitia of the aorta is reported here for the first time, although Gharagozlou, Mobedi and Akhavan (2003) described pulmonary coenurosis previously in goats from Iran. In addition, their phylogenetic analysis of mitochondrial deoxyribonucleic acid (CO1 and ND1) showed that C. gaigeri and Coenurus cerebralis were not different species. In the present study, the location of coenururi in the central nervous system and other extra-cranial tissues (e.g. 
the skeletal muscles and subcutaneous and visceral organs) was observed. This finding supports the hypothesis that C. cerebralis and C. gaigeri are not different species. Genetic characterisation and phylogenetic position is a diagnostic tool for identification of various species of metacestodes (Huttner et al. 2008). Godara et al. (2011) reported simultaneous coenuri in the cerebrum and liver of goats but found no coenuri in the skeletal muscles or subcutaneous tissues. They also concluded that $\mathrm{C}$. cerebralis and $\mathrm{C}$. gaigeri are not different species. In other studies with regard to goats, coenuri were reported only from subcutaneous and skeletal muscles. Patro et al. (1997) found coenuri only in the subcutaneous tissues of goats. Shivapraksh and Thimma Reddy (2009) reported an outbreak of multiple subcutaneous coenuri in a herd of goats. They identified the subcutaneous coenuri as C. gaigeri because of their extra-cranial locations (i.e. in the neck, prescapular region, abdomen and limbs). Jain and Shah (1982) described that the subcutaneous location is an uncommon site for coenuri in sheep when compared to the brain and spinal cord.

In our study, histopathological findings in the skeletal muscles included degenerative and necrotic changes, hyalinisation and myositis, which are in agreement with a previous report (Oryan et al. 2010). In addition, the coenuri in the cerebrum caused perivascular cuffing, neuronal degeneration, demyelination, neuronophagia, satellitosis, diffuse microgliosis and astrocytosis. Similar findings were described in previous studies (Godara et al. 2011; Nourani \& Pirali Kheirabadi 2009; Oryan, Moghaddar \& Gaur 1994).

In this study, no significant difference was observed between the prevalence of coenurosis during the spring and summer (10 infected goats in spring and nine in summer). The observation is in agreement with that of Sharma, Singh and Tiwari (1998), who described C. cerebralis infections in sheep not to be associated with seasonal variation, but rather to occur throughout the year. Cancedda et al. (2002) showed that coenurosis incidence in Sardinia was highest during spring and the autumn. In Jordan, Abo-Shehada et al. (2002) reported 11 of 12 infected heads during spring and autumn. The survival of the T. multiceps eggs in pasture, distribution of the final host and grazing behaviour of the intermediate hosts are factors that influence the rate of infection (Desouky, Badawy \& Refaat 2011). The difference with regard to incidence in the different agro-climatic zones may be attributed to diverse geographical, sociological and ecological factors (Sharma \& Chauhan 2006).

\section{Conclusion}

The present study has indicated various predilection sites in coenurosis, including the brain, the skeletal muscles and other organs and tissues. The finding points to C. cerebralis and C. gaigeri being synonyms for the larval stage of T. multiceps in various animal species. Further studies are necessary to clarify the tendency of coenuri to occur in the subcutaneous tissues, skeletal muscles and visceral organs of goats.

\section{Acknowledgement}

This research was financially supported by the research council of Shahid Bahonar University, Kerman.

\section{Competing interests}

The authors declare that they have no financial or personal relationship(s) which may have inappropriately influenced them in writing this paper.

\section{Authors' contributions}

R.K. (Shahid Bahonar University) was the project leader and pathologist, M.S. (Shahid Bahonar University) was responsible for the project design, sample collection and performing some experiments, S.A. (Islamic Azad University) performed pathology and M.M. (Shahid Bahonar University) was responsible for parasitological study.

\section{References}

Abo-Shehada, M.N., Jebreen, E., Arab, B., Mukbel, R. \& Torgerson, P., 2002, 'Prevalence of Taenia multiceps in sheep in northern Jordan', Preventive Veterinary Medicine 55, 201-207. http://dx.doi.org/10.1016/S0167-5877(02)00056-9

Alim, M.A., Islam, M.K., Rahman, M.M., Khan, M.A. \& Mondan, M.M., 2002, 'Further observation on metacestodiosis in black Bengal goat in Bangladesh', Pakistan Journal of Science and Industrial Research 45, 330-333.

Avcioglu, H., Yildirim, A., Duzlu, O., Inci, A., Kapakin Terim, K.A. \& Balkaya, I., 2011 'Prevalence and molecular characterization of bovine coenurosis from Eastern Anatolian region of Turkey', Veterinary Parasitology 176, 59-64. http://dx.doi. org/10.1016/j.vetpar.2010.10.033, PMid:21074326

Bhalla, N.P. \& Negi, M.S., 1962, 'Occurrence of Multiceps multiceps over the heart of a goat', Indian Veterinary Journal 39, 55-56.

Boch, J. \& Supperer, R., 1983, Veterinärmedizinische Parasitologie [Veterinary Medicine Parasitology], 3rd edn., Paul Parey, Berlin.

Bohrmann, R., 1990, 'Coenurus in the muscles of a gemsbok (Oryx gazella)', Veterinary Parasitology 36, 353-356. http://dx.doi.org/10.1016/0304-4017(90)90049-H

Cancedda, M.G., Scala, A., Chighine, C., Piazza, C., Sardo, D., Varcasia, A. et al., 2002, Quadri clinici della cenurosi ovina e diagnosi differenziale con altre neuropatologie [Clinical coenurosis of sheep and differential diagnosis with other neuropathologies]. Atti Società Italiana di Patologia ed Allevamento degli Ovini e Caprini (SIPAOC) 15, 16

Desouky, E.A., Badawy, A.I. \& Refaat, R.A., 2011, 'Survey on coenurosis in sheep and goats in Egypt', Veterinaria Italiana 47, 333-340. PMid:21947971

El Sinnari, A., Tageldin, M.H. \& Sumri, H.S., 1999, 'Outbreak of coenurosis (Taenia species) in Anglonubian goats in the Sultanate of Oman', Veterinary Record 144, 296-297. http://dx.doi.org/10.1136/vr.144.11.296, PMid:10204227

Fraser, G.M. (ed.), 1991, The Merck Veterinary Manual. Handbook of diagnosis, therapy, and disease prevention and control for veterinarians, Merck, Rahway, NJ.

Gharagozlou, M.J., Mobedi, I. \& Akhavan, P., 2003, 'A pathological and parasitological study of Coenurus gaigeri infestation of goats from Iran', Indian Journal of Veterinary Pathology 27, 95-97.

Godara, R., Borah, M.K., Sharma, R.L. \& Jangir, B.L., 2011, 'Caprine coenurosis with special reference to hepatic coenurosis', Comparative Clinical Pathology 20, 277280. http://dx.doi.org/10.1007/s00580-010-1108-0

Gosh, R.C., Dubey, S., Mandal, S.C. \& Sharma, N., 2005, 'Occurrence of Coenurus gaigeri cyst in a goat', Indian Veterinary Journal 82, 90-91.

Hago, B.E.D. \& Abu-Samra, M.T., 1980, 'A case of Multiceps gaigeri coenurosis in a goat', Veterinary Parasitology 7, 191-194. http://dx.doi.org/10.1016/03044017(80)90023-0

Huttner, M., Nakao, M., Wassermann, T., Siefert, L., Boomker, J.D.F., Dinkel, A. et al., 2008, 'Genetic characterization and phylogenetic position of Echinococcus felidis Ortlepp, 1937 (Cestoda: Taeniidae) from the African lion', International Journal Ortlepp, 1937 (Cestoda: Taeniidae) from the African lion', International Journal
for Parasitology 38, 861-868. http://dx.doi.org/10.1016/j.ijpara.2007.10.013, PMid:18062973

Islam, S., Kalita, D., Bhuyan, D., Rahman, T. \& Saleque, A., 2006, 'Ocular coenurosis in a goat', Journal of Veterinary Parasitology 20, 53-55.

Jain, P.C. \& Shah, H.L., 1982, 'A note on the occurrence of Coenurus gaigeri from the gluteal muscles of sheep', Livestock Advisors 7, 31-32.

Moghaddar, N., 2007, 'Occurrence of Coenurus gaigeri in goats in Shiraz, Iran', Journal of Applied Animal Research 31, 83-84. http://dx.doi.org/10.1080/09712119.20 07.9706635

Nourani, H. \& Pirali Kheirabadi, K., 2009, 'Cerebral coenurosis in a goat: Pathological findings and literature review', Comparative Clinical Pathology 18, 85-87. http:// dx.doi.org/10.1007/s00580-008-0742-2 
Oryan, A., Nazifi, S., Sharifiyazdi, H. \& Ahmadnia, S., 2010, 'Pathological, molecular, and biochemical characterization of Coenurus gaigeri in Iranian native goats',
Journal of Parasitology 96, 961-967. http://dx.doi.org/10.1645/GE-2399.1, PMid:20469949

Oryan, A., Moghaddar, N. \& Gaur, S.N.S., 1994, 'Metacestodes of sheep with special reference to their epidemiological status, pathogenesis and economic
implications in Fars Province of Iran', Veterinary Parasitology 51, 231-240. http:// dx.doi.org/10.1016/0304-4017(94)90160-0

Patro, D.N., Suhani, B., Sahoo, D.K., Nanda, S.K., Pradhan, P.K. \& Nayak, B.C., 1997 'Incidence of generalized Coenurus gaigeri infection in a goat farm', Indian Veterinary Journal 74, 68-69.

Ramadan, R.O., Magzoub, M. \& Adam, S.E.I., 1973, 'Clinicopathological effects in a Sudanese goat following massive natural infection with Coenurus gaigeri cysts', Tropical Animal Health and Production 5, 196-199. http://dx.doi.org/10.1007/ BF02251390, PMid:4802430

Schuster, R.K., Sivakumar, S. \& Wieckowsky, T., 2010, 'Non-cerebral coenurosis in goats', Parasitology Research 107, 721-726. http://dx.doi.org/10.1007/s00436010-1919-6, PMid:20502917

Sharma, D.K. \& Chauhan, P.P.S., 2006, 'Coenurosis status in Afro-Asian region: A review', Small Ruminant Research 64, 197-202. http://dx.doi.org/10.1016/j. smallrumres.2005.05.021

Sharma, D.K., Singh, N. \& Tiwari, H.A., 1998, 'Prevalence and pathology of coenurosis in organized goat farms', Journal of Veterinary Parasitology 12, 30-32.
Sharma, D.K., Sanil, N.K., Agnihotri, M.K. \& Singh, N., 1995, 'Subcutaneous coenurosis in Barbary goat', Indian Veterinary Journal 72, 217-218.

Shivapraksh, B.V. \& Thimma Reddy, P.M., 2009, 'An outbreak of multiple subcutaneous Coenurus cysts in goats', Journal of Veterinary Parasitology 23, 199-200.

Soulsby, E.J.L., 1982, Helminths, arthropods and protozoa of domesticated animals, Bailliere Tindall, London.

Uslu, U. \& Guclu, F., 2007, 'Prevalence of Coenurus cerebralis in sheep in Turkey', Medycyna Weterynaryjna 63, 678-680.

Verster, A.J.M., 1965, 'Review of Echinococcus species in South Africa', Onderstepoort Journal of Veterinary Research 32, 7-118. PMid:5335506

Verster, A., 1969, 'A taxonomic revision of the genus Taenia Linnaeus, 1758 s. str', Onderstepoort Journal of Veterinary Research 36, 3-58. PMid:5407584

Verster, A. \& Bezuidenhout, J.D., 1972, 'Taenia multiceps larva from a gemsbok', Onderstepoort Journal of Veterinary Research 39, 123-124. PMid:4664320

Verster, A. \& Tustin, R.C., 1982, 'Treatment of the larval stage of Taenia multiceps with praziquantel', Journal of the South African Veterinary Association 53, 107-108. PMid:7120267

Verster, A. \& Tustin, R.C., 1990, 'Treatment of cerebral coenuriosis in sheep with praziquantel', Journal of the South African Veterinary Association 61, 24-26. PMid:2269985

Webbe, G., 1994, 'Human cysticercosis: parasitology, pathology, clinical manifestations and available treatment', Pharmacology and Therapeutics 64, 175-200. http:// dx.doi.org/10.1016/0163-7258(94)90038-8 